\title{
Rhizobium and Mycorrhizal Fungal Species Improved Soybean Yield Under Drought Stress Conditions
}

\author{
Ozede N. Igiehon ${ }^{1}$ (D) . Olubukola O. Babalola ${ }^{1}$ D
}

Received: 16 June 2020 / Accepted: 16 February 2021 / Published online: 9 March 2021

(c) The Author(s) 2021

\begin{abstract}
Food insecurity is a serious threat due to the increasing human population particularly in developing countries and may be minimized by the use of microbial inoculants. Also, the problems of excessive use of chemical fertilizers including the fact that most of the fertilizers are relatively non-affordable and that they also contaminate underground and surface water, which can increase the risk of blue baby syndrome in infants and stomach cancer in adults. There is therefore the need to harness a more cost-effective, eco-friendly and beneficial biological agents to improve crops productivity especially under drought conditions. Thus, in this study, the ability of rhizobia species and arbuscular mycorrhizal fungi (AMF) to enhance soybean tolerance to drought stress under water regimens of 100, 70 and $40 \%$ field capacity (FC) was investigated. It was observed that co-inoculation of soybean with Rhizobium spp. (R1+R3) as well as with Rhizobium spp. and mycorrhizal consortium (R1+R3MY) had significant impacts $(P<0.05)$ on soybean leaf relative water content and electrolyte leakage, respectively. The levels of proline increased mainly in microbially amended soybean exposed to drought stress. Plants inoculated with $\mathrm{R} 1+\mathrm{R} 3 \mathrm{MY}$ showed the highest number of spore and \% mycorrhization in all the water regimes. At $40 \% \mathrm{FC}, \mathrm{R} 1+\mathrm{R} 3 \mathrm{MY}$ treatment was found to promote soybean growth compared to the non-inoculated plants. Similarly, at 40\% FC, R1+R3MY inoculum had the greatest impacts on soybean pod number, seed number, seed fresh weight, highest seed number per pod and seed dry weight while at 70\% water stress, significant impacts of R1MY inoculation were observed on pod number, pod fresh weight and seed dry weight. These results revealed that co-inoculation of rhizobia and mycorrhizal fungi can be harnessed biotechnologically to proffer solution to food insecurity.
\end{abstract}

\section{Introduction}

Drought stress is one of the most damaging abiotic factors affecting global food security. Drought stress might range from moderate and short to very severe and protracted duration, limiting crop yield [1]. This abiotic stress is estimated to cause severe growth problems in plants for over $50 \%$ of the arable lands by the end of the next three decades [2-4]. For instance, drought interfere with plant normal functions by affecting its water potential and turgor leading to changes in physiological and morphological parameters $[5,6]$. Growth parameters under drought stress have been investigated in many crops such as barley, maize, wheat, rice and soybean $[7,8]$. Water content and fresh weight

Olubukola O. Babalola

olubukola.babalola@nwu.ac.za

Food Security and Safety Niche, Faculty of Natural and Agricultural Science, North-West University, Private Mail Bag X2046, Mmabatho 2735, South Africa are among the common growth parameters that are influenced by drought stress [9]. Another problem of drought stress is that it influences the availability and movement of nutrients, since soil nutrients are transported to the roots by water. Drought therefore reduces nutrient diffusion as well as mass flow of soluble nutrients such as $\mathrm{Si}, \mathrm{Ca}, \mathrm{Mg}$, sulfate and nitrate $[10,11]$ and these problems can be surmounted through the use of rhizobia and mycorrhizal fungal species.

Furthermore, several studies involving the use of valuable soil microorganisms (e.g. rhizobia) to reduce drought stress have been investigated [12]. Other studies have demonstrated that inoculation with AMF enhanced water absorption in numerous plants that were subjected to drought stress [13, 14]. Specifically, under harsh conditions, AMF mycelia can penetrate larger volume of soil than host plant roots, therefore increasing water absorption and transport to the root and other plant parts which eventually improves the osmotic regulation, cellular and physiological effects in plants [15].

Co-inoculation of soybean plants with AM fungal and Rhizobium species enhanced nodule biomass in a semi-arid 
environment [16]. Similarly, co-inoculation of Glomus spp. with Rhizobium leguminosarum significantly enhanced plant biomass and other plant parameters of Pisum sativum [17] while in another study, dual inoculation of Rhizobium spp. and mycorrhizal consortium reduced drought stress and enhanced shoot relative water content, fat content and yield of soybean plants [16]. In addition, studies have also shown the effectiveness of co-inoculation of specific rhizobia and mycorrhizal fungi in a controlled environment $[18,19]$ but more work with different rhizobia and mycorrhizal combinations is needed in this aspect. However, single inoculation of Rhizobium spp. improved soybean seed germination under drought stress imposed by $4 \%$ poly-ethylene glycol under a controlled environment [8]. Inoculation of pea with Variovorax paradoxus 5C-2 under drought stress resulted in higher seed yield, seed $\mathrm{N}$ accumulation, seed number and nodulation restoration [20]. Bacteria with 1-aminocyclopropane-1-carboxylate deaminase (ACC) deaminase producing potential reduced the effects of drought on growth, yield and ripening of pea under controlled and field conditions [21] while inoculation of Pisum sativum with Pseudomonas fluorescens biotype G (ACC-5) under arid condition increased root length and water uptake from soil. Increased nodulation by $\mathrm{N}$-fixing bacterial symbionts eliminated drought-induced reduction in nodulation and seed $\mathrm{N}$ content. Co-inoculation of a leguminous plant Cicer arietinum with Mesorhizobium ciceris, Pseudomonas sp. and Bacillus sp. significantly enhanced seed germination, shoot and root length of the plant over the non-inoculated control [22].

Thus, the aim of this study is to determine the effects of single and co-inoculation of rhizobia and AMF on soybean growth and productivity exposed to drought stress under a controlled environment with the prospect of harnessing the effective microbial inoculants for field application.

\section{Materials and Methods}

\section{Experimental and Soil Collection Sites}

Soil samples for pot experiment were collected from NorthWest University farm while the greenhouse experiment was also conducted in North-West University, South Africa.

\section{Experimental Set-Up and Soybean Growth Conditions}

Soil used for the greenhouse experiment was homogenized and sieved using a $5.6 \mathrm{~mm}$ diameter round sieve. Sieved soil samples were packed in autoclavable plastics and sterilized at $121{ }^{\circ} \mathrm{C}$ for $30 \mathrm{~min}$ in an autoclave (SA-300VL Autoclave, Taiwan.
The experimental trial was set-up using 3 factorial completely randomized design (CRD) and the three factors included rhizobia, arbuscular mycorrhizal fungi (AMF) consortium and drought or water stress. 'The experiment was conducted in a greenhouse under natural light'.

Three drought regimes were used in this study namely: 100, 70 and $40 \%$ field capacity (FC). The water stress levels ( 70 and $40 \%$ FC) were determined by the method described by Zarik et al. [23] with little modifications. Six (6) small plastic pots were weighed (W1), the plastic pots $+100 \mathrm{~g}$ of soil were weighed (W2) and weight of $100 \mathrm{~g}$ of soil only (W3) was obtained by subtracting W2 from W1. The first plastic pot with soil was watered with $40 \mathrm{ml}$ of water until 'soil saturation', the second, third, fourth, fifth and sixth pots were watered with $30,20,15$ and 10 and $5 \mathrm{ml}$ of water, respectively. Watered pots were sealed with plastic and kept on the lab shelf. The sixth pot watered with $5 \mathrm{ml}$ of water was not waterlogged after observing for 3 days and was weighed again to obtain its saturated weight and water holding capacity of the soil was subsequently calculated from this pot using the formula:

Water holding capacity $=\frac{\text { Saurated weight }- \text { dry weight }}{\text { dry weight }} \times 100 \%$

Then, the water holding capacity (which represents the amount of water needed to saturate the soil) of the $8 \mathrm{~kg}$ of soil (used for the greenhouse experiment) was obtained from the water holding capacity obtained for the 6th pot above by direct proportionality.

The two rhizobia Rhizobium sp. strain R1 with the accession no. MG309875 (https://www.ncbi.nlm.nih.gov/search/ all/?term=.\%20MG309875\%20) and Rhizobium cellulosilyticum strain R3 with the accession no. MG309874 (https ://www.ncbi.nlm.nih.gov/search/all/?term=MG309874) used in this study were isolated in our previous work from Bambara groundnut rhizosphere and identified by molecular methods. In the previous work, these bacteria were also found to possess some plant growth promoting traits and were tolerant to in vitro osmotic stress induced by stressstimulant [polyethylene glycol (PEG)] while the AMF consortium [consisted of Paraglomus occulum (molecular determination), Gigaspora gigantea, Funneliformis mosseae (previously Glomus mosseae), Claroideoglomus etunicatum (previously Glomus etunicatum) and Rhizophagus clarus (previously Glomus clarum)] was obtained from Department of Biochemistry and Microbiology, Rhodes University, Grahamstown, South Africa.

Rhizobium sp. strain R1 and $R$. cellulosilyticum strain $\mathrm{R} 3$ were grown and harvested according to the method of Prakamhang et al. [24] with little modifications. Fresh cultures of the bacteria were grown in flasks containing $1000 \mathrm{ml}$ nutrient broth in a shaker incubator (FMH200 
Instruments) at $180 \mathrm{rpm}$ for 6 days. Fully grown culture was centrifuged at $1000 \times g$ for $10 \mathrm{~min}$ and washed twice in a sterile $0.85 \%$ saline solution. The initial optical density (OD) of the bacteria was adjusted to $1.3 \mathrm{OD}$ and the bacterial titer was adjusted to $30 \times 10^{9}$ and $31 \times 10^{9} \mathrm{CFU}$ (colony forming unit) $\mathrm{ml}^{-1}$ for Rhizobium sp. strain $\mathrm{R} 1$ and $R$. cellulosilyticum strain $\mathrm{R} 3$, respectively.

The greenhouse experiment was conducted in plastic pots $(30 \mathrm{~cm}$ diameter, height $29 \mathrm{~cm}$ ) containing $8 \mathrm{~kg}$ of dried and sterile soil. The experiment which had a total number of 192 replicates comprised 24 treatments and each treatment had 8 replicates. Soybean seeds (PAN 1532 $\mathrm{R}$ cultivar) were washed in sterile distilled water, surface sterilized in $75 \%$ ethanol and then $1 \%$ sodium hypochlorite and rinsed severally to totally remove the chemicals. For single rhizobial inoculation, approximately 240 surface sterilized soybean seeds were inoculated with $200 \mathrm{ml}$ of Rhizobium sp. strain R1and R. cellulosilyticum strain R3 suspension each, co-inoculation was done by amending approximately 240 surface sterilized soybean seeds with $100 \mathrm{ml}$ of Rhizobium sp. strain R1 and R. cellulosilyticum strain R3 suspension each and $200 \mathrm{ml}$ of sterile $0.85 \%$ saline water was added to approximately 480 surface sterilized soybean seeds for AMF consortium and control treatments. Flasks containing seeds were agitated (to thoroughly mix the seeds with the inocula) in a shaker incubator at $180 \mathrm{rpm}$ at $28 \pm 2^{\circ} \mathrm{C}$ for $24 \mathrm{hr}$. Thereafter, the liquid suspension was decanted and air-dried on a sterile aluminum foil paper in a sterilized laminar flow cabinet (Filta Matix Laminar Flow Carbinet) prior to sowing. All the greenhouse pots containing $8 \mathrm{~kg}$ of sterile soil were watered with $360 \mathrm{ml}$ of water (100\% FC) before sowing. Five seeds were sowed per pot. Treatments involving AM fungi were inoculated by placing a tea spoonful (approximately $5 \mathrm{~g}$ ) of AMF consortium in the soil before adding the seeds. Soybean bean plants were thinned to two plants per pot two weeks after emergence. One of the plants was marked and termed as 'plant for sample collection (PSC)' used for assessment of physiological, biochemical and \% mycorrhization parameters while the second plant was allowed to grow to maturity which was used to assessed the below-ground-above-ground and/or morphological parameters. All the water treatments (100, 70 and $40 \%$ FC) were fully watered to the field capacity after every $72 \mathrm{~h}$ for approximately three weeks after germination and thereafter, drought or water stress was initiated in the 70 and $40 \%$ FC treatments and were watered after every $48 \mathrm{~h}$ with 252 and $144 \mathrm{ml}$ of water respectively but we continued watering the $100 \% \mathrm{FC}$ treatments (the watering control) with $360 \mathrm{ml}$ of water. Three weeks after initiating drought stress, pots were watered after every $72 \mathrm{~h}$ until termination of the experiment so as to increase drought stress.

\section{Physicochemical Analysis of Soil}

The physicochemical analysis of the soil for the greenhouse experiment was determined following previously reported methods [16].

\section{Parameters Measured}

\section{Relative Water Content}

The leaf relative water content was determined according to the methods described by Aroca et al. [25] with little modifications and the 'youngest fully developed leaves of each plant' were used. Fresh leaf samples were weighed (Fresh weight-FW) and placed in test tubes saturated with water and kept at $4{ }^{\circ} \mathrm{C}$ for $48 \mathrm{~h}$. Thereafter, the leaf samples were weighed again to obtain the turgid weight (TW) and ovendried at $60{ }^{\circ} \mathrm{C}$ for $24 \mathrm{~h}$ and dry weights (DW) were obtained. The leaf relative water content was calculated as follows:

Leaf relative water content $(\%)=\frac{(\mathrm{FW}-\mathrm{DW})}{(\mathrm{TW}-\mathrm{DW})} \times 100$

where FW—fresh weight, DW—dry weight and TW—turgid weight.

\section{Electrolyte Leakage}

The youngest leaves of approximately the same size from the youngest branch 'toward the distal end' were collected from the sampling plants and thoroughly rinsed with de-ionized water to remove electrolytes attached to the leaf surfaces. Leaf samples were placed in $45 \mathrm{ml}$ falcon tubes containing $10 \mathrm{ml}$ deionized of $\mathrm{H}_{2} \mathrm{O}$ and incubated on a shaker incubator at $28 \pm 2^{\circ} \mathrm{C}$ for $24 \mathrm{~h}$. Subsequently, electrical conductivity of the liquid suspension $(\mathrm{Lt})$ was obtained using conductivity meter (PL-700AL, Taiwan) and samples were autoclaved at $120{ }^{\circ} \mathrm{C}$ for $1200 \mathrm{~s}$, cooled to $25^{\circ} \mathrm{C}$ and electrical conductivity of the liquid (L0) was obtained. The electrolyte leakage was calculated as follows [26]:

Electrolyte leakage $(\%)=\frac{\mathrm{Lt}}{\mathrm{L} 0} \times 100 \%$

where $\mathrm{Lt}$-electrical conductivity of the liquid suspension prior to autoclaving and $\mathrm{L}_{0}$-electrical conductivity of the liquid suspension after autoclaving.

\section{Determination of Leaf Proline Content}

Proline concentration was determined according the methods of Ortiz et al. [26] with little modifications. Briefly, $1.25 \mathrm{~g}$ of ninhydrin was dissolved in $20 \mathrm{ml}$ of $6 \mathrm{M}$ phosphoric acid 
and $30 \mathrm{ml}$ of glacial acetic acid by heating on a hot-plate with agitation. The solution was allowed to cool and kept at $4{ }^{\circ} \mathrm{C}$ and the solution became stable after $24 \mathrm{~h}$. Approximately $500 \mathrm{mg}$ of fresh soybean leaf sample was ground in $10 \mathrm{ml}$ of $3 \%$ aqueous sulfo-salicyclic acid and centrifuged at $10000 \times g$ for $10 \mathrm{~min}$. Two $\mathrm{ml}(2 \mathrm{ml})$ of the supernatant was reacted with $2 \mathrm{ml}$ of glacial acetic acid and $2 \mathrm{ml}$ of acidninhydrin solution in $45 \mathrm{ml}$ falcon tubes at $100{ }^{\circ} \mathrm{C}$ in a water bath for $60 \mathrm{~min}$ and the reaction was stopped in an ice box. Four $\mathrm{ml}(4 \mathrm{ml})$ of toluene was added to extract the mixture and agitated vigorously for 15-20 s in a shaker incubator at $250 \mathrm{rpm}$. The mixture was kept in the dark for $30 \mathrm{~min}$ and the "chromophore containing toluene was aspirated from the aqueous phase and the absorbance was read at $520 \mathrm{~nm}$ using toluene for a blank'. The concentration of proline was estimated from a standard curve 'established with a reference proline solution'. Briefly, $1 \mathrm{mg} / \mathrm{ml}$ stock solution of proline was prepared by weighing $10 \mathrm{mg}$ of proline (DL-Proline, China) in $10 \mathrm{ml}$ of sterile water. 0, 50, 100, 150, 200, 250, $300 \mu \mathrm{l}$ of the stock solution was pipetted into seven tubes containing $300,250,200,150,100,50$ and $0 \mu$ of sterile water, respectively. The mixtures were then reacted with 2 $\mathrm{ml}$ of glacial acetic acid and $2 \mathrm{ml}$ of acid-ninhydrin solution in $45 \mathrm{ml}$ falcon tubes at $100{ }^{\circ} \mathrm{C}$ in a water bath for $60 \mathrm{~min}$ and the reaction was stopped in an ice box. The mixture was vigorously agitated using a vortex (Vortex Genie, U.S.A) after adding $4 \mathrm{ml}$ of toluene. The mixture was kept in the dark for $30 \mathrm{~min}$ and the absorbance of the proline-containing upper layer 'was read at $520 \mathrm{~nm}$ using toluene for a blank' and proline standard curve was plotted from the absorbance values.

\section{Chlorophyll Content}

Chlorophyll content was taken from the youngest fully developed leaf at the distal end of PSC using a chlorophyll content meter (CCM-200 plus).

\section{AMF Spore Estimation}

AM fungal spores were estimated by wet sieving and decanting methods as described by Pacioni [27] with little modifications. Fifty g (50 g) of soil close to soybean root region was collected and mixed in $500 \mathrm{ml}$ of sterile distilled water. The mixture was passed through a series of sieves of different sizes stacked together in an increasing order from the base to the top: 53, 63, 106 and $212 \mu \mathrm{m}$. The trapped fungal spores on the $53 \mu \mathrm{m}$ were rinsed into a $1.5 \mathrm{ml}$ vials and centrifuged at $1800 \mathrm{rpm}$ for $5 \mathrm{~min}$. The supernatant $(1 \mathrm{ml})$ was mixed with $60 \%$ sucrose $(0.5 \mathrm{ml})$ in a $1.5 \mathrm{ml}$ vial and centrifuged at $1800 \mathrm{rpm}$ for $5 \mathrm{~min}$. The supernatant-containing
AMF spores was decanted in a cleaned Petri-dish and examined under a stereomicroscope at X3 and X4 magnification.

\section{Percentage Mycorrhizal Colonization}

Soybean roots were cut into pieces of $1 \mathrm{~cm}$ long and cleared in $10 \% \mathrm{KOH}$ at $121{ }^{\circ} \mathrm{C}$ for $15 \mathrm{~min}$ in an autoclave (SA$300 \mathrm{VL}$, Taiwan). Roots were covered with $2 \% \mathrm{HCl}$ for 30 min after rinsing severally with distilled water. Root samples were subsequently covered with trypan blue solution (trypan blue solution consisted of $0.82 \mathrm{~g}$ trypan blue powder, $640 \mathrm{ml}$ distilled water, $520 \mathrm{ml}$ lactic acid and $480 \mathrm{ml}$ glycerol) and autoclaved at $121{ }^{\circ} \mathrm{C}$ for $15 \mathrm{~min}$. Root samples were then de-stained in 50\% glycerol and examined under a stereomicroscope [16].

\section{Below-Ground-Above-Ground Parameters}

After harvesting soybean plants grown to maturity, data such as shoot height, shoot width, branch number, leaf number, taproot length, lateral root number, plant fresh weight, shoot dry weight and root dry weight were obtained according to the method described by Masciarelli et al. [28].

\section{Above-Ground Yield Parameters}

In this study, the following yield parameters were considered such as pod number, pod fresh weight, seed number, seed fresh weight, highest seed number per pod and seed dry weight. Seed fresh weight was determined by weighing seeds on a weighing machine. Seeds were oven-dried at 65 ${ }^{\circ} \mathrm{C}$ for $48 \mathrm{~h}$ and weighed on a weighing machine to obtain the dry weights.

\section{Statistical Analyses}

In this experiment, the effects of rhizobia and water stress (drought) factors on soybean plant growth in the greenhouse were statistically analyzed. Test for homogeneity of data were done and data were normalized prior to using general linear model analysis of variance (ANOVA) to evaluate the impacts of rhizobia inoculants on soybean growth at three different water regimens or levels of 100,70 and $40 \%$ using the following treatments which were replicated 8 times: Control $_{100 \% \mathrm{FC}}, \mathrm{R} 1_{100 \% \mathrm{FC}}, \mathrm{R} 3_{100 \% \mathrm{FC}}, \mathrm{MY}, \mathrm{R} 1 \mathrm{MY}{ }_{100 \% \mathrm{FC}}$, R3MY ${ }_{100 \% \mathrm{FC}}, \mathrm{R} 1+\mathrm{R} 3{ }_{100 \% \mathrm{FC}}, \mathrm{R} 1+\mathrm{R} 3 \mathrm{MY}{ }_{100 \% \mathrm{FC}}$. Control ${ }_{70 \% \mathrm{FC}}, \mathrm{R} 1_{70 \% \mathrm{FC}}, \mathrm{R} 3_{70 \% \mathrm{FC}}, \mathrm{MY}_{70 \% \mathrm{FC}}, \mathrm{R} 1 \mathrm{MY}{ }_{70 \% \mathrm{FC}}, \mathrm{R} 3 \mathrm{MY}$ $70 \% \mathrm{FC}, \mathrm{R} 1+\mathrm{R} 3{ }_{70 \% \mathrm{FC}}, \mathrm{R} 1+\mathrm{R} 3 \mathrm{MY}{ }_{70 \% \mathrm{FC}}$.Control ${ }_{40 \% \mathrm{FC}}, \mathrm{R} 1$ $40 \% \mathrm{FC}, \mathrm{R} 3{ }_{40 \% \mathrm{FC}}, \mathrm{MY}_{40 \% \mathrm{FC}}, \mathrm{R} 1 \mathrm{MY}{ }_{40 \% \mathrm{FC}}, \mathrm{R} 3 \mathrm{MY}{ }_{40 \% \mathrm{FC}}$, $\mathrm{R} 1+\mathrm{R} 3_{40 \% \mathrm{FC}}, \mathrm{R} 1+\mathrm{R} 3 \mathrm{MY}{ }_{40 \% \mathrm{FC}}$ 
Differences between mean (post hoc test) was determined by Duncan's multiple-range test (DMRT) [29] and differences were significant at $p \leq 0.05$. DMRT was used in this study because is relatively more useful than other Post Hoc multiple comparison tests (such as least significant difference-LSD) when comparing larger pairs of means, particularly when the mean values are in a table.

\section{Results}

\section{Soil Physicochemical Parameters}

The soil that was used in this study contain sandy soil (70\%) and silt (8\%). The percentage of total nitrogen was low compared to 1.260 and $3.190 \%$ observed for organic carbon and organic matter, respectively (Table 1). Also, potassium (K) was $406 \mathrm{mg} / \mathrm{kg}$ while the soil $\mathrm{pH}$ which was 7.390 was within the $\mathrm{pH}$ range that supports bacterial growth.

\section{Leaf Relative Water Content}

Generally, the non-inoculated soybean plants were slightly affected $(p>0.05)$ with drought stresses $(40 \%$ FC) compared to soybean plants inoculated with rhizobia and mycorrhizal fungi. In R1 + R3 treatment, soybean plants exposed to $40 \%$ FC maintained high relative water content in their leaves compared to the non-inoculated (control) plants (Fig $1)$.

\section{Leaf Electrolyte Leakage}

As regards electrolyte leakage, with the exception of soybean plants amended with R1+R3MY, soybean plants inoculated with $R$. cellulosilyticum strain R3 (R3) showed a better result at $70 \% \mathrm{FC}$ than other inoculated soybean plants. But at this level of water stress, significant increase $(p<0.05)$ was

Table 1 Physicochemical parameters of homogenized soil samples used for the greenhouse experiment
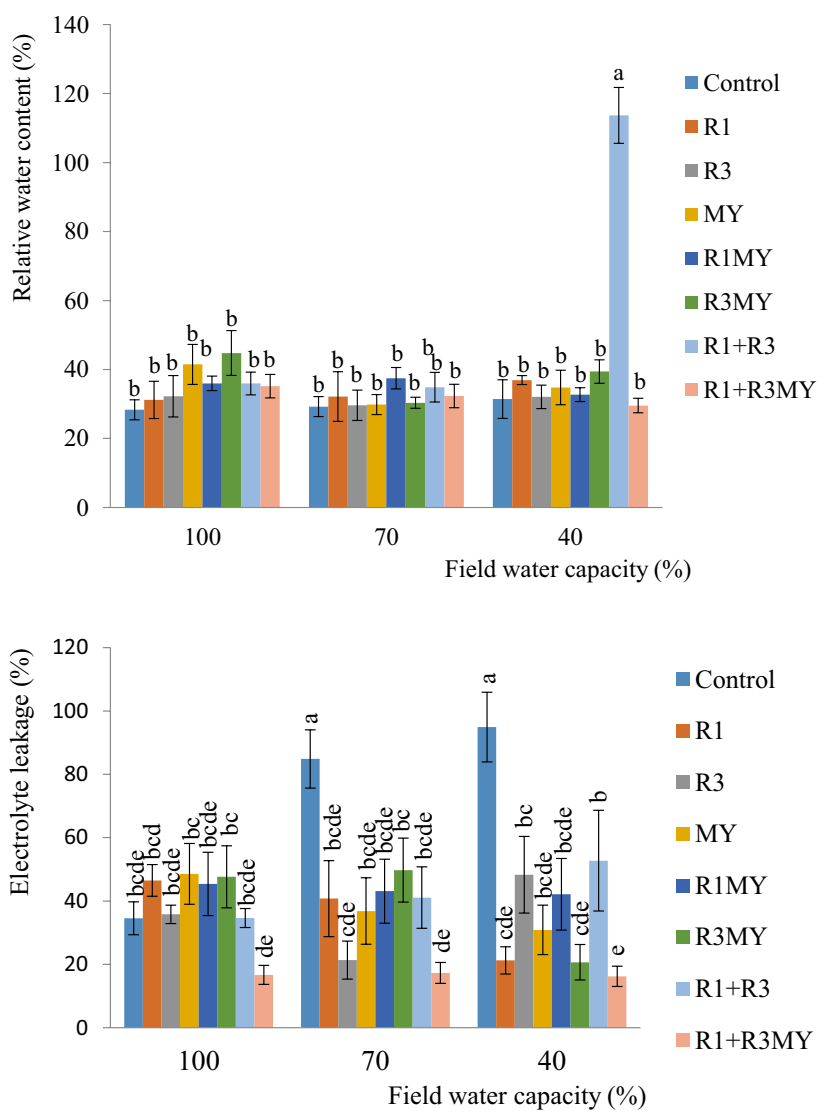

Fig. 1 Relative water content and electrolytes of leaves of inoculated and non-inoculated soybean plants exposed to a 4-week period of drought stress. Control-non-inoculated treatment, R1-Rhizobium sp. strain R1, R3-R. cellulosilyticum strain R3, MY-mycorrhizal consortium, R1MY - Rhizobium sp. strain R1 and mycorrhizal fungal consortium, R3MY $-R$. cellulosilyticum strain R3 and mycorrhizal consortium, R1+R3-Rhizobium sp. strain R1 and R. cellulosilyticum strain R3, R1+R3MY-Rhizobium sp. strain R1, R. cellulosilyticum strain R3 and mycorrhizal consortium. Number of replicates $(n)=8$. Data represent mean $\pm \mathrm{SE}$

observed in non-inoculated treatment; the electrolyte leakage however decreased in 100\% FC (Fig. 1). In all the water stress levels, the control treatments were the most negatively impacted particularly at $40 \%$ FC which showed electrolyte leakage of $94.9 \%$.

\section{Proline Content of Soybean Leaves}

Accumulation of proline in soybean leaves was highest in plants exposed to $40 \%$ water stress. Soybean plants dually inoculated with R3MY was found to accumulate the highest concentration of proline which was different $(p>0.05)$ from the non-inoculated (control) plants that produced the lowest amount of proline under 40\% FC (Fig. 2). Also, all the microbially treated soybean plants produced more proline 

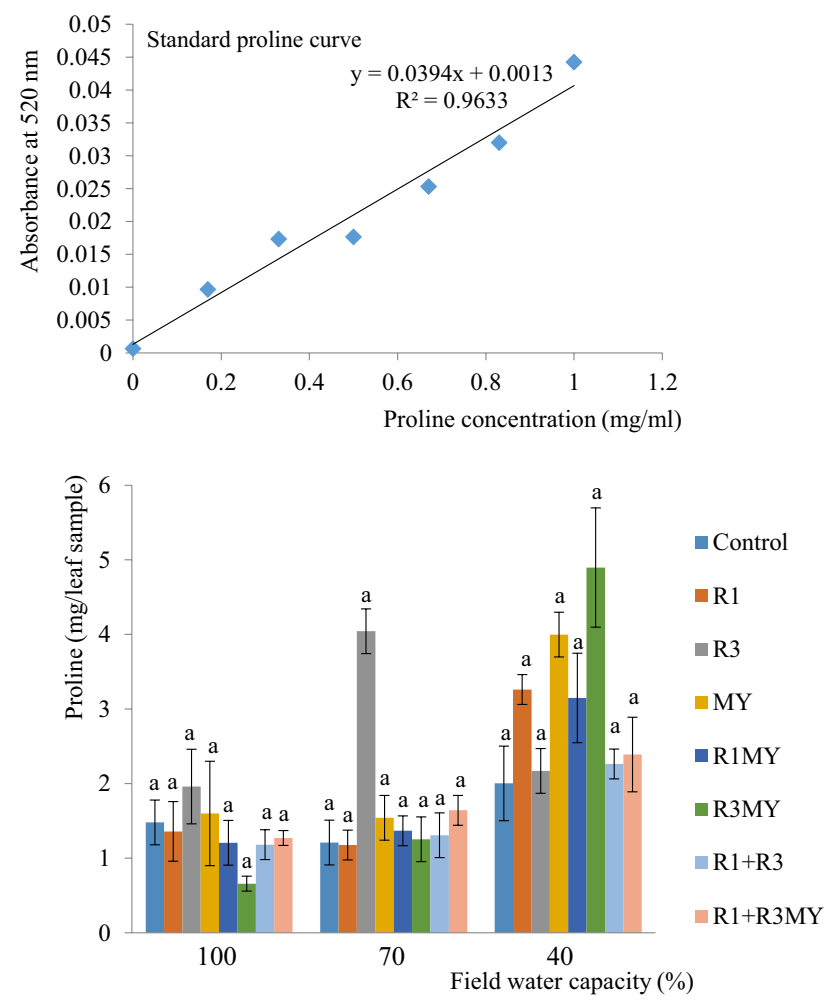

Fig. 2 Proline accumulation in leaves of inoculated and non-inoculated soybean plants exposed to a 6-week period of drought stress. Control-non-inoculated treatment, R1-Rhizobium sp. strain R1, $\mathrm{R} 3-R$. cellulosilyticum strain R3, MY-mycorrhizal consortium, R1MY-Rhizobium sp. strain R1 and mycorrhizal fungal consortium, $\mathrm{R} 3 \mathrm{MY}-R$. cellulosilyticum strain R3 and mycorrhizal consortium, $\mathrm{R} 1+\mathrm{R} 3-$ Rhizobium sp. strain R1 and $R$. cellulosilyticum strain R3, $\mathrm{R} 1+\mathrm{R} 3 \mathrm{MY}-$ Rhizobium sp. strain R1, R. cellulosilyticum strain R3 and mycorrhizal consortium. Number of replicates $(n)=8$. Data represent mean $\pm \mathrm{SE}$

than the non-inoculated treatment under $40 \%$ FC. However, the non-inoculated soybean plants grown in $100 \% \mathrm{FC}$ accumulated more proline $(p>0.05)$ than the non-inoculated soybean plants subjected to $70 \% \mathrm{FC}$.

\section{Chlorophyll Content of Soybean Leaves}

In soybean plants subjected to $40 \%$ water stress, R1, MY, R1MY and $\mathrm{R} 1+\mathrm{R} 3 \mathrm{MY}$ inoculants were observed to increase the chlorophyll content of soybean leaves more than the control plants (exposed to 40, 70 and $100 \%$ FC) and their counterparts subjected to 70 and $100 \%$ water stress (Fig. 3). The non-inoculated (control) soybean plants grown in 70\% FC showed the lowest chlorophyll content (11.375 CCI-chlorophyll content index) among all the plant treatments subjected to $70 \%$ water stress. At this water stress level, the greatest impact on chlorophyll content was detected in soybean plants dually amended with R1MY and $\mathrm{R} 1+\mathrm{R} 3 \mathrm{MY}$

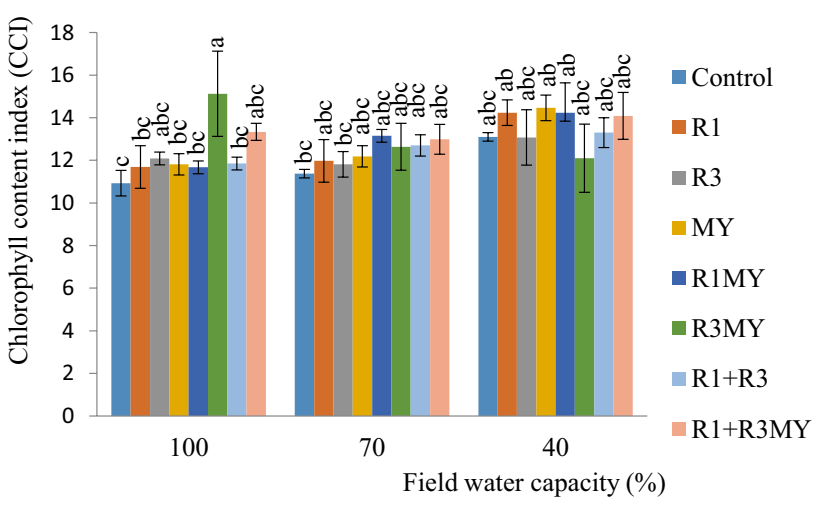

Fig. 3 Chlorophyll content of leaves of inoculated and non-inoculated soybean plants exposed to a 3-week period of drought stress. Control-non-inoculated treatment, R1-Rhizobium sp. strain R1, R3-R. cellulosilyticum strain R3, MY-mycorrhizal consortium, R1MY-Rhizobium sp. strain R1 and mycorrhizal fungal consortium, $\mathrm{R} 3 \mathrm{MY}-R$. cellulosilyticum strain R3 and mycorrhizal consortium, $\mathrm{R} 1+\mathrm{R} 3$ - Rhizobium sp. strain R1 and $R$. cellulosilyticum strain R3, $\mathrm{R} 1+\mathrm{R} 3 \mathrm{MY}-$ Rhizobium sp. strain R1, R. cellulosilyticum strain R3 and mycorrhizal consortium. Number of replicates $(n)=8$. Data represent mean $\pm \mathrm{SE}$

\section{Spore Number and Percentage Colonization of Mycorrhizal Fungi}

The treatment with the microbial combination $\mathrm{R} 1+\mathrm{R} 3 \mathrm{MY}$ showed the highest number of spore in all the water levels $(100,70,40 \%$ FC) while the lowest spore number was recorded for treatment solely inoculated with mycorrhizal consortium (MY). Control, R1, R3 and R1 + R3 treatments did not show presence of fungal spore (Fig. 4) since these treatments were not amended with mycorrhizal fungi (Fig. 4a).

Similar results were also observed for percentage (\%) mycorrhization and the highest colonization levels were revealed in soybean plants co-inoculated with $\mathrm{R} 1+\mathrm{R} 3 \mathrm{MY}$ in all the water regimes. Mycorrhizal colonization (Fig. 4b) was observed to be more in the treatments co-inoculated with rhizobia and mycorrhizal fungi and coincidentally, colonization level in soybean plants inoculated with R1MY was approximately $58 \%$ in treatments subjected to 70 and $40 \%$ FC.

\section{Microbial Effects on Below-Ground and Above-Ground Parameters of Soybean Plants}

Microbial (rhizobia and mycorrhizal) inoculation enhanced the growth of soybean plants virtually in all the water regimes compared to the non-inoculated (control) treatments (Table 2). We noticed that under different water regimes, inoculated soybean plants maintained higher below-groundabove-ground biomass (such as shoot height, shoot width, 


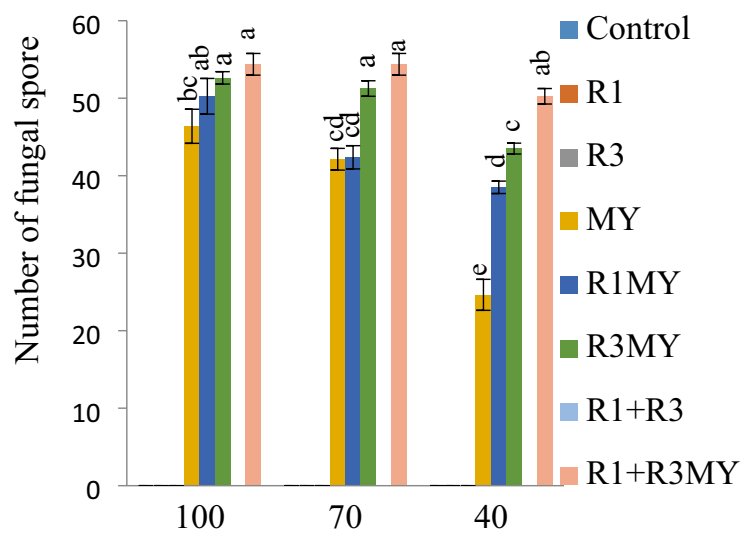

Field water capacity $(\%)$

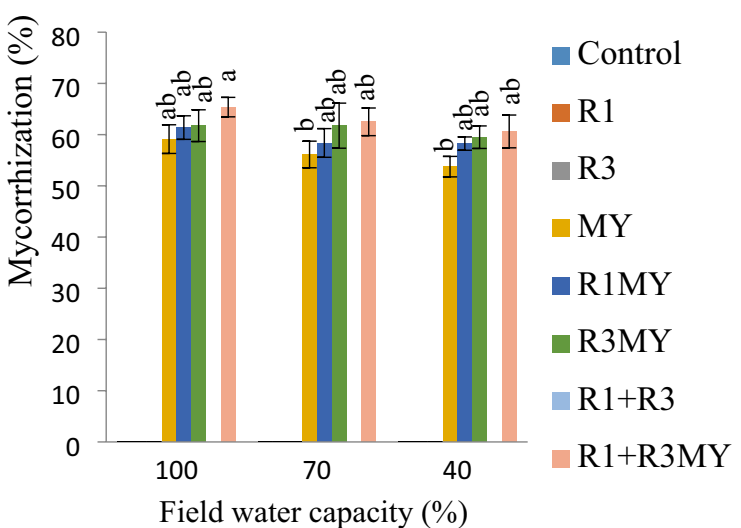

Fig. 4 Spore number and percentage colonization level of mycorrhizal of inoculated and non-inoculated soybean plants exposed to a 10 -week period of drought stress. Control-non-inoculated treatment, $\mathrm{R} 1-$ Rhizobium sp. strain R1, R3-R. cellulosilyticum strain R3, MY - mycorrhizal consortium, R1MY-Rhizobium sp. strain R1 and mycorrhizal fungal consortium, R3MY $-R$. cellulosilyticum strain R3 and mycorrhizal consortium, R1+R3-Rhizobium sp. strain R1 and

branch number, leaf number, taproot length, taproot width, lateral root number, plant fresh weight, shoot dry weight and root dry weight) compared to the non-inoculated plants (Table 2).

\section{Microbial Effects on Soybean Yield}

Irrespective of the water treatment, rhizobial and mycorrhizal inoculation increased soybean yield components such as pod number, pod fresh weight, seed number, seed fresh weight, highest seed number per pod and seed dry weight. For 40\% FC, R1 + R3MY inoculum had the greatest impact on pod number, seed number, seed fresh weight, highest seed number per pod and seed dry weight (Table 3). But R1MY and R1 + R3 were observed to have the greatest effects on
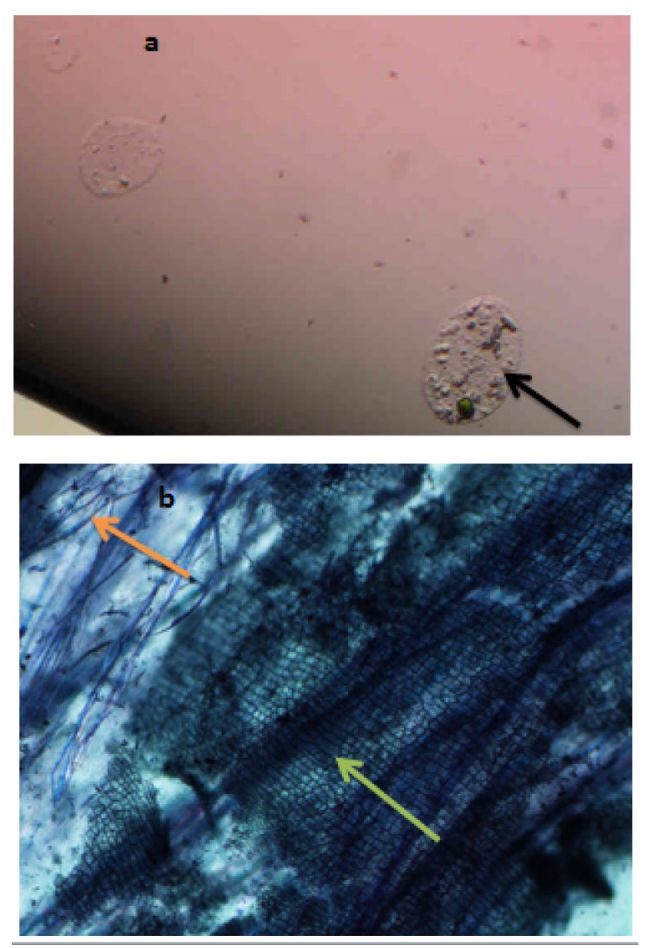

a. $\quad 70.2: 49.0 \mathrm{~mm} \mathrm{~b} .70 .5: 55.5 \mathrm{~mm}$

R. cellulosilyticum strain $\mathrm{R} 3, \mathrm{R} 1+\mathrm{R} 3 \mathrm{MY}$ - Rhizobium $\mathrm{sp}$. strain $\mathrm{R} 1$, $R$. cellulosilyticum strain $\mathrm{R} 3$ and mycorrhizal consortium. a Represents AMF spores (70.2:49.0 mm), b represents root colonized with AMF (70.5:55.5 mm). Black, green and orange arrows point towards fungal spores, arbuscule and hyphal, respectively. Number of replicates $(n)=8$. Data represent mean $\pm \mathrm{SE}$

pod fresh weight with a mean weight of $0.16 \mathrm{~g}$ each at this level of water stress. However, the non-inoculated plants and plants that were singly inoculated with R1 and R3 did not produce seeds even though they had pods. Significant effects $(p<0.05)$ of $\mathrm{R} 1+\mathrm{R} 3 \mathrm{MY}$ inoculation were not only observed on seed number, seed fresh weight and seed dry weight but also on pod number and highest number per pod compared to other microbial and non-microbial or control treatments subjected to the $40 \% \mathrm{FC}$.

On the other hand, we observed that the effects of $\mathrm{R} 1+\mathrm{R} 3 \mathrm{MY}$ treatment decreased at $70 \% \mathrm{FC}$, but the decrease was only significant for highest seed number per pod and seed dry weight (Table 3). At this level of water stress, significant impacts $(p<0.05)$ of R1MY inoculation were observed on pod number, pod fresh weight, seed 


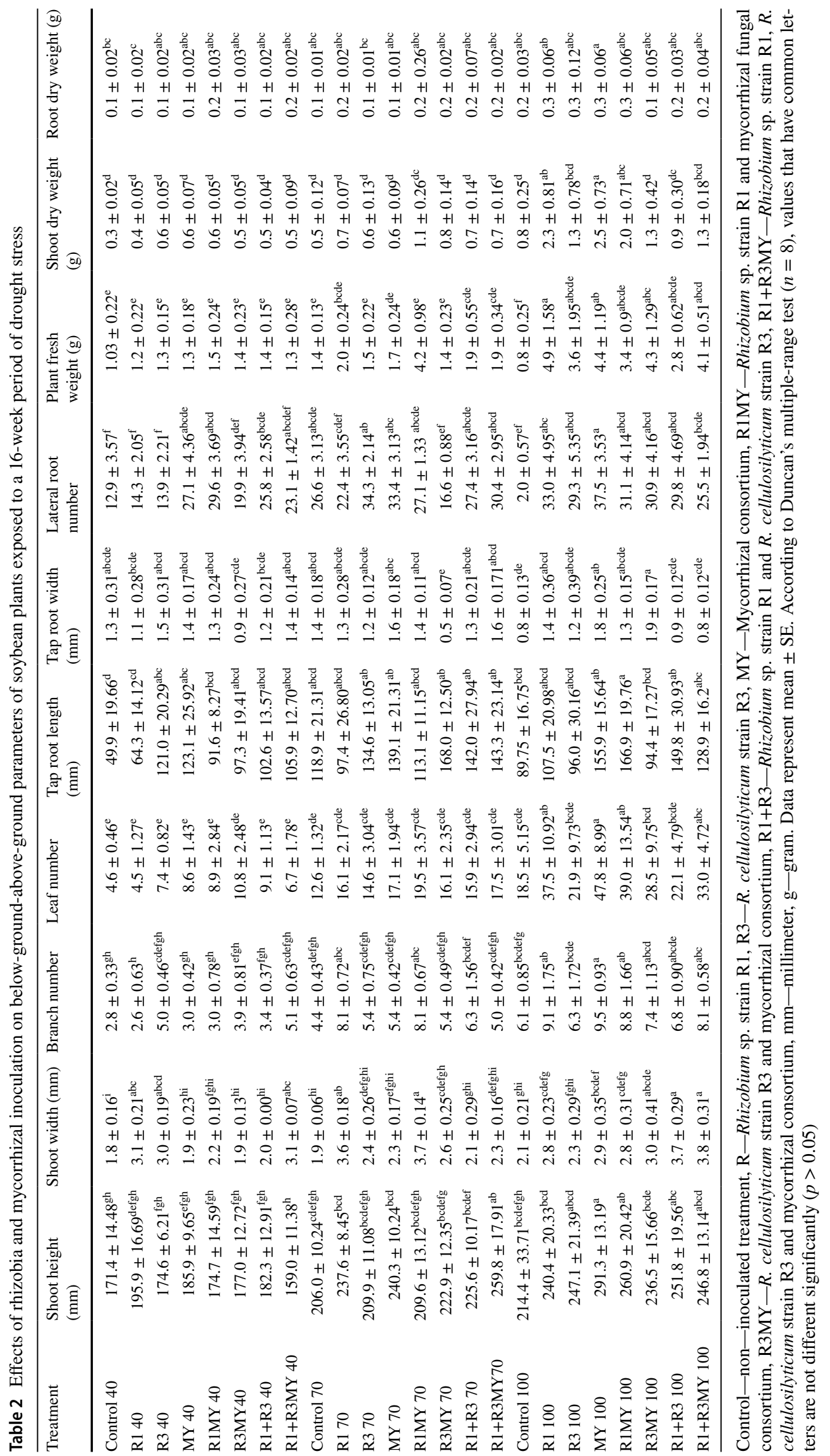


Table 3 Effects of rhizobia and mycorrhizal inoculation on the yield components of soybean plants exposed to a 16-week period of drought stress

\begin{tabular}{|c|c|c|c|c|c|c|}
\hline Treatment & Pod number & Pod fresh weight (g) & Seed number & Seed fresh weight $(\mathrm{g})$ & $\begin{array}{l}\text { Highest seed } \\
\text { number per pod }\end{array}$ & Seed dry weight $(\mathrm{g})$ \\
\hline Control 40 & $0.50 \pm 0.33^{\mathrm{de}}$ & $0.01 \pm 0.00^{\mathrm{d}}$ & $0.00 \pm 0.00^{\mathrm{d}}$ & $0.00 \pm 0.00^{c}$ & $0.00 \pm 0.00^{f}$ & $0.00 \pm 0.00^{\mathrm{b}}$ \\
\hline R1 40 & $0.25 \pm 0.25^{\mathrm{e}}$ & $0.03 \pm 0.03^{\mathrm{d}}$ & $0.00 \pm 0.00^{\mathrm{d}}$ & $0.00 \pm 0.00^{c}$ & $0.00 \pm 0.00^{\mathrm{f}}$ & $0.00 \pm 0.00^{\mathrm{b}}$ \\
\hline R3 40 & $0.13 \pm 0.44^{\mathrm{e}}$ & $0.01 \pm 0.13^{\mathrm{d}}$ & $0.00 \pm 0.00^{\mathrm{d}}$ & $0.00 \pm 0.00^{c}$ & $0.00 \pm 0.00^{f}$ & $0.00 \pm 0.00^{\mathrm{b}}$ \\
\hline MY 40 & $0.88 \pm 0.38^{\text {bcde }}$ & $0.13 \pm 0.20^{\mathrm{cd}}$ & $0.510 \pm 0.59^{\mathrm{d}}$ & $0.04 \pm 0.09^{c}$ & $0.75 \pm 0.38^{\text {bcdef }}$ & $0.03 \pm 0.03^{\mathrm{b}}$ \\
\hline R1MY 40 & $0.50 \pm 0.87^{\mathrm{de}}$ & $0.16 \pm 0.61^{\mathrm{cd}}$ & $0.63 \pm 1.36^{\mathrm{d}}$ & $0.05 \pm 0.31^{\mathrm{c}}$ & $0.50 \pm 0.31^{\mathrm{def}}$ & $0.01 \pm 0.12^{\mathrm{b}}$ \\
\hline R3MY 40 & $0.38 \pm 0.35^{\mathrm{de}}$ & $0.05 \pm 0.33^{\mathrm{d}}$ & $0.25 \pm 0.74^{\mathrm{d}}$ & $0.01 \pm 0.07^{\mathrm{c}}$ & $0.25 \pm 0.41^{\mathrm{ef}}$ & $0.02 \pm 0.02^{\mathrm{b}}$ \\
\hline $\mathrm{R} 1+\mathrm{R} 340$ & $0.25 \pm 0.25^{\mathrm{e}}$ & $0.16 \pm 0.11^{\mathrm{cd}}$ & $0.75 \pm 0.49^{\mathrm{d}}$ & $0.07 \pm 0.05 c$ & $0.50 \pm 0.33^{\mathrm{def}}$ & $0.03 \pm 0.02^{\mathrm{b}}$ \\
\hline $\mathrm{R} 1+\mathrm{R} 3 \mathrm{MY} 40$ & $0.57 \pm 0.43^{\text {bcde }}$ & $0.10 \pm 0.08^{\mathrm{cd}}$ & $1.14 \pm 0.73^{\mathrm{bcd}}$ & $0.10 \pm 0.07^{\mathrm{bc}}$ & $1.14 \pm 0.73^{\mathrm{abcd}}$ & $0.093 \pm 0.08^{\mathrm{ab}}$ \\
\hline Control 70 & $1.12 \pm 0.35^{\mathrm{bcde}}$ & $0.12 \pm 0.04^{\mathrm{cd}}$ & $0.50 \pm 0.19^{\mathrm{d}}$ & $0.05 \pm 0.19^{c}$ & $0.50 \pm 0.19^{\mathrm{def}}$ & $0.01 \pm 0.00^{\mathrm{b}}$ \\
\hline $\mathrm{R} 170$ & $1.25 \pm 0.37^{\mathrm{bcde}}$ & $0.27 \pm 0.09^{\mathrm{cd}}$ & $0.88 \pm 0.39^{\mathrm{d}}$ & $0.06 \pm 0.03^{c}$ & $0.75 \pm 0.31^{\text {bcdef }}$ & $0.04 \pm 0.02^{\mathrm{b}}$ \\
\hline R3 70 & $0.88 \pm 0.44^{\mathrm{bcde}}$ & $0.25 \pm 0.13^{\mathrm{cd}}$ & $1.13 \pm 0.58^{\mathrm{dc}}$ & $0.11 \pm 0.07^{\mathrm{bc}}$ & $0.75 \pm 0.37^{\text {bcdef }}$ & $0.03 \pm 0.02^{\mathrm{b}}$ \\
\hline MY 70 & $1.00 \pm 0.38^{\text {bcde }}$ & $0.53 \pm 0.21^{\mathrm{bcd}}$ & $1.50 \pm 0.59^{\mathrm{bcd}}$ & $0.19 \pm 0.09^{b c}$ & $1.00 \pm 0.38^{\mathrm{abcdef}}$ & $0.06 \pm 0.03^{\mathrm{b}}$ \\
\hline R1MY70 & $2.50 \pm 0.87^{\mathrm{abcde}}$ & $1.17 \pm 0.61^{\mathrm{abc}}$ & $2.88 \pm 1.35^{\mathrm{abcd}}$ & $0.50 \pm 0.31^{\mathrm{abc}}$ & $1.25 \pm 0.31^{\mathrm{abcde}}$ & $0.19 \pm 0.12^{\mathrm{ab}}$ \\
\hline R3MY 70 & $1.13 \pm 0.35^{\mathrm{bcde}}$ & $0.95 \pm 0.33^{\mathrm{abcd}}$ & $1.13 \pm 0.74^{\mathrm{dc}}$ & $0.07 \pm 0.07^{\mathrm{c}}$ & $0.63 \pm 0.42^{\text {cdef }}$ & $0.03 \pm 0.02^{\mathrm{b}}$ \\
\hline $\mathrm{R} 1+\mathrm{R} 370$ & $2.13 \pm 0.58^{\mathrm{abcde}}$ & $0.65 \pm 0.24^{\mathrm{bcd}}$ & $3.00 \pm 0.96^{\mathrm{abcd}}$ & $0.28 \pm 0.11^{\mathrm{abc}}$ & $1.25 \pm 0.37^{\mathrm{abcde}}$ & $0.14 \pm 0.05^{\mathrm{ab}}$ \\
\hline $\mathrm{R} 1+\mathrm{R} 3 \mathrm{MY} 70$ & $1.88 \pm 0.39^{\mathrm{abcde}}$ & $0.56 \pm 0.25^{\mathrm{bcd}}$ & $2.25 \pm 0.77^{\mathrm{bcd}}$ & $0.26 \pm 0.15^{\mathrm{bc}}$ & $1.25 \pm 0.31^{\mathrm{abcde}}$ & $0.08 \pm 0.05^{\mathrm{b}}$ \\
\hline Control 100 & $0.17 \pm 0.11^{\text {cde }}$ & $0.17 \pm 0.11^{\mathrm{cd}}$ & $0.50 \pm 0.27^{\mathrm{d}}$ & $0.03 \pm 0.02^{c}$ & $0.50 \pm 0.28^{\mathrm{def}}$ & $0.01 \pm 0.01^{\mathrm{b}}$ \\
\hline R1 100 & $4.38 \pm 1.99^{\mathrm{a}}$ & $1.82 \pm 0.89^{\mathrm{a}}$ & $6.25 \pm 2.96^{\mathrm{a}}$ & $0.78 \pm 0.41^{\mathrm{a}}$ & $1.75 \pm 0.49^{\mathrm{abc}}$ & $0.23 \pm 0.12^{\mathrm{ab}}$ \\
\hline R3 100 & $2.75 \pm 1.19^{\mathrm{abcde}}$ & $0.79 \pm 0.37^{\mathrm{abcd}}$ & $2.63 \pm 1.05^{\mathrm{bcd}}$ & $0.29 \pm 0.13^{\mathrm{abc}}$ & $1.13 \pm 0.39^{\text {abcdef }}$ & $0.08 \pm 0.04^{\mathrm{b}}$ \\
\hline MY 100 & $3.38 \pm 1.71^{\mathrm{abc}}$ & $0.99 \pm 0.53^{\mathrm{abcd}}$ & $2.51 \pm 1.54^{\mathrm{abcd}}$ & $0.27 \pm 0.19^{\mathrm{abc}}$ & $2.88 \pm 0.39^{\mathrm{abcdef}}$ & $0.37 \pm 0.07^{\mathrm{ab}}$ \\
\hline R1MY 100 & $3.13 \pm 0.58^{\mathrm{abcd}}$ & $0.76 \pm 0.21^{\mathrm{bcd}}$ & $2.25 \pm 0.90^{\mathrm{bcd}}$ & $0.22 \pm 0.09^{\mathrm{bc}}$ & $0.88 \pm 0.29^{\mathrm{abcdef}}$ & $0.06 \pm 0.03^{\mathrm{b}}$ \\
\hline R3MY100 & $3.50 \pm 1.28^{\mathrm{ab}}$ & $1.17 \pm 0.46^{\mathrm{abc}}$ & $5.00 \pm 2.33^{\mathrm{ab}}$ & $0.61 \pm 0.32^{\mathrm{ab}}$ & $2.00 \pm 0.38^{\mathrm{a}}$ & $0.35 \pm 0.28^{\mathrm{a}}$ \\
\hline $\mathrm{R} 1+\mathrm{R} 3100$ & $2.88 \pm 0.95^{\mathrm{abcde}}$ & $0.80 \pm 0.24^{\mathrm{abcd}}$ & $2.88 \pm 0.74^{\mathrm{abcd}}$ & $0.31 \pm 0.09^{\mathrm{abc}}$ & $1.75 \pm 0.31^{\mathrm{abc}}$ & $0.09 \pm 0.03^{\mathrm{ab}}$ \\
\hline $\mathrm{R} 1+\mathrm{R} 3 \mathrm{MY} 100$ & $4.13 \pm 1.16^{\mathrm{a}}$ & $1.38 \pm 0.46^{\mathrm{ab}}$ & $4.63 \pm 1.31^{\mathrm{abc}}$ & $0.62 \pm 0.28^{\mathrm{ab}}$ & $1.88 \pm 0.48^{\mathrm{ab}}$ & $0.23 \pm 0.12^{\mathrm{ab}}$ \\
\hline
\end{tabular}

Control—non-inoculated treatment, R1-Rhizobium sp. strain R1, R3-R. cellulosilyticum strain R3, MY-Mycorrhizal consortium, R1MYRhizobium sp. strain R1 and mycorrhizal fungal consortium, R3MY-R. cellulosilyticum strain R3 and mycorrhizal consortium, R1+R3Rhizobium sp. strain R1 and $R$. cellulosilyticum strain R3, R1+R3MY-Rhizobium sp. strain R1, R. cellulosilyticum strain R3 and mycorrhizal consortium, $40-40 \%$ field water capacity, $70-70 \%$ field water capacity, $100-100 \%$ field water capacity, g-gram. Data represent mean \pm SE. According to Duncan's multiple-range test $(n=8)$, values that have common letters are not different significantly $(p>0.05)$

number and seed dry weight (Table 3). Unlike in $40 \%$ FC, the control, R1 and R3 treatments produced seeds at $70 \%$ FC. Overall, $70 \%$ water stress negatively affected the control soybean plants compared to the microbially amended plants (Table 3). In particular, the mean pod fresh weight, seed number, seed fresh weight, highest seed number per pod and seed dry weight observed in the control treatment corresponds to $0.12 \mathrm{~g}, 0.5,0.05 \mathrm{~g}, 0.05$ and $0.01 \mathrm{~g}$ but only the highest seed number per pod was significantly less than all inoculated treatments while others were not significantly less $(p>0.05)$ than some of the inoculated treatments (Table 3 ).

A similar pattern was noticed in inoculated and noninoculated plants grown in $100 \%$ water level. R1 treatment produced more seed with the greatest pod and seed fresh weight. Generally, under this water regime, the non-inoculated plants were less productive compared to the other treatments as depicted by the yield components measured (Table 3).

\section{Discussion}

In this study, physiological, biochemical and morphological parameters connected to drought tolerance in soybean plants amended with rhizobia and mycorrhizal consortium under water stress conditions were investigated.

Our results indicated that the singly and dually inoculated soybean plants showed different levels of percentage relative water content (\% RWC) under 40, 70 and $100 \%$ FC. However, water stress reduced the RWC in non-inoculated soybean plants exposed to both water stressed treatments and plants inoculated with R1 + R3MY grown in 40\% FC (Fig. 1). Overall, the current study unveiled that microbial 
inoculations enhanced RWC in soybean plant leaves under water stress.

RWC is used to evaluate water level balance in plants and it is a dependable strategy by which the level of osmotic stress is determined [23]. Indeed, RWC helps to determine the level of water in plants which is pointer to the metabolic state in plant tissues. Under water stress, RWC is usually considered an excellent indicator of drought stress tolerance in different plants [16]. Thus, in this study, MY treatment was able to increase RWC from 29.8 (in $70 \%$ FC) to $34.8 \%$ (in $40 \%$ FC). This confirms the reports that mycorrhizal fungi increased leaf RWC [30, 31]. In addition, some single and dual inoculations similarly led to increase in RWC and this increase was pronounced in plants treated with $\mathrm{R} 1+\mathrm{R} 3$. The mechanisms associated with this increase in RWC by microbial isolates is linked to as reported by Zarik et al. [23] "stomatal regulation through hormonal signals [31]; higher stomatal conductance and transpiration fluxes [32]; indirect effect of improved phosphate and other nutrient uptake [33]; greater osmotic adjustment [34] and/or higher root hydraulic conductivity [13]" than non-inoculated (control) plants.

Plant responses to water stress have also been evaluated based on physiological values derived from electrolyte leakage [26] which in the present study were lowest particularly in soybean plants dually inoculated with rhizobial spp. and mycorrhizal consortium (R1 + R3MY) and highest in the non-inoculated plants (Fig. 1). The low level of electrolyte leakage is a pointer to "cell membranes stability" and drought stress tolerance [35]. Cell membrane is very crucial in monitoring the efficacy of plant root-microbial interactions [36]. Most of the microbial inocula used in this study reduced plant membrane damaged in drought stressed soybean plants since they showed relatively low \% electrolyte leakage compared to the non-inoculated plants. This result is in agreement with the results obtained by Ortiz et al. [26] who reported low electrolyte leakage values in Trifolium repens amended with selected (PGPR) and AMF in arid soil environment.

The amino acid proline is an essential 'osmo-protectant osmolyte' produced by plants to improve osmosis and prevent water loss $[23,37]$. The proline concentration in leaves was lower in non-inoculated soybean plants than in rhizobial and mycorrhizal inoculated soybean plants under severe drought (Fig. 2). Under this drought condition, significant accumulation of proline was observed in the leaves of soybean plants treated with the dual inoculum R3MY (Fig. 2). This finding corresponds to the result of Ortiz et al. [26] who reported significant proline accumulation in some plant treatments dually inoculated with microbial species leading to a reduction in the osmotic potential of the plant cells and consequently enhanced uptake of water to 'maintain osmotic balance' [38]. Also, the concentration of proline accumulated by soybean plants treated with
MY under severe drought condition was approximately 4 $\mu \mathrm{mol} / \mathrm{g}$ dry weight which was comparatively higher than that of the non-mycorrhized treatments (control, R1, R3, $\mathrm{R} 1+\mathrm{R} 3$ ). This result disagrees with the conclusions of Zarik et al. [23]; Manoharan et al. [39] and Wu and Xia [34] who observed less proline content in the leaves of mycorrhized Cupressus atlantica, vagiegata and orange plants respectively than in non-mycorrhized plants grown under moderate and severe drought stresses. Furthermore, under moderate drought stress condition, soybean plants treated with R1 + R3MY were shown to accumulate the highest level of proline while the lowest level was found in R1 treatment. Contrary results were found in the wellwatered plant treatments where the highest and lowest proline concentrations were produced by plants inoculated with R3 and R3MY, respectively.

Surprisingly, lower chlorophyll content was observed in virtually all soybean plants grown in $100 \% \mathrm{FC}$ and increased with increasing drought stress (Fig. 3). Overall, R3MY treatment and non-inoculated plants grown in $100 \%$ FC showed the highest (15.2 CCI) and lowest (10.9 CCI) chlorophyll content, respectively. Chlorophyll is an important component that plays a vital role in the process of photosynthesis in plants [40]. Considering the different water levels, chlorophyll content negatively correlated with below-groundabove-ground productivity, implying that as the drought stress increased, chlorophyll content increased and plant productivity decreased.

Furthermore, we found that the number of mycorrhizal spore (Fig. 4) and \% mycorrhization in this study were dominant in soybean treated with R1 + R3MY under 40, 70 and $100 \%$ FC. Also, soybean root colonization or \% mycorrhization (Fig. 4) was positively correlated with RWC (Fig. 1) and seed number of soybean plants inoculated with MY, R3MY and R1 + R3MY (Table 3) indicating enhancement of plant water status and productivity. Perhaps, mycorrhizal fungi may have contributed to drought avoidance capacity of these treatments, thus resulting in water stress alleviation in soybean plants. The increase in seed number and other morphological components in soybean plants inoculated with MY, R1MY, R3MY, R1 + R3MY may partly be ascribed to mycorrhizal colonization (Fig. 4b) and RWC (especially for MY, R1MY and R3MY treatments at 40\% FC), signifying that plant water content was efficiently enhanced by this plant-microbial interactions resulting in enhanced productivity. This finding agrees with the results of Aliasgharzad et al. [19] who reported that an increase in \% mycorrhization led to an increase in RWC in soybean plants inoculated with both Bradyrhizobium japonicum and Glomus etunicatum.

It was reported in our previous work [41] that belowground interactions between plants and rhizobacteria/AMF can trigger responses that may affect above-ground plant components. But in the present study, it became evident 
that below-ground interactions among rhizobia, mycorrhizal fungi and soybean plants under stressed condition improved the productivity of most of the above-ground components such as shoot height, shoot width, branch number, leaf number, shoot dry weight, pod number, pod fresh weight, seed number, seed fresh weight, highest seed number per pod and seed dry weight (Tables 2 and 3 ).

At $40 \%$ FC, significant promotion of soybean plant growth under severe drought stress by R1 + R3MY inoculation depicted by increased in shoot width and branch number (Table 2) could be as a result of the synergistic interaction between the microbial species and mutualistic interaction between the inoculum and soybean plant roots [41]. This treatment in addition to the dual inoculum R1MY greatly affected root dry weight, although the effect was only significantly different $(p<0.05)$ from plants inoculated with R1. Similarly, under severe drought stress, taproot length was greatly affected by R3 inoculum and this result somewhat supported the outcome of our previous work (data not shown) in which R3 significantly affected soybean seedling root fresh and dry weight and number of lateral root in a growth chamber experiment where PEG was used as a drought factor. But in this study, under severe drought stressed condition, R3 treatments produced lateral roots with a mean value of 13.9 which was less than that produced by other microbial treatments but higher than that of noninoculated plants (Table 2).

On the contrary, R3 treatments produced the highest (34.3) number of lateral roots under moderate drought stress (70\% FC) which further supports our previous PEG experiment results (Table 2). Like in severe drought condition, R1 $+\mathrm{R} 3 \mathrm{MY}$ inoculum also enhanced soybean growth under moderate drought stress since it had the greatest effect on soybean shoot height under this condition (Table 2). Belowground taproot length received the greatest impacts from both R1 + R3MY and MY inocula compared to other treatments. Under this condition, we observed that below-ground synergistic interaction between Rhizobium sp. strain R1 and mycorrhizal consortium (RIMY) outstandingly impacted soybean shoot width, branch number, leaf number and shoot number.

For the well-watered treatments, it was found that MY glaringly enhanced soybean plant shoot height with a mean value of $291.3 \mathrm{~mm}$ (Table 2) and the non-inoculated plants showed the poorest shoot development as they presented the lowest (214 and $2.1 \mathrm{~mm}$ ) shoot height and shoot width, respectively. Thus, based on the shoot height and shoot width evaluation, the non-inoculated or control plants produced soybean plants with the lowest shoot biomass in all the water regimes (Table 2).

One of the indicators of sustainable agriculture and/or food security is increase in agricultural produce [18, 42]. Our present study has shown that combination of rhizobia and mycorrhizal fungal consortium resulted in increased yield (soybean seed number) under severe and moderate stressed conditions in a controlled environment (Table 3 ). Particularly, R1 + R3MY treatments significantly $(p<$ $0.05)$ produced more seeds in $40 \% \mathrm{FC}$ than other treatments (Table 3). The non-inoculated (control) plants and plants amended with R1 and R3 did not produced seeds under this condition probably because the absence of PGPR (in the control plants) and single inoculation (in R1 and R3 treated plants) could not ameliorate the detrimental effects of drought stress to the extent of empowering the plants to produced seeds even though these treatments produced pods. It was reported in our previous studies $[43,44]$ that abiotic stresses such as drought, heat and salinity are part of the factors that militate against crop growth, development and yield. The impacts of these abiotic stresses may be abated by below-ground plant-microbial interactions [41]. Tripartite mutualistic interactions with AMF fungi and Rhizobium species [41] is therefore important for increased productivity in soybean [18] and the impacts of co-inoculation with mycorrhizal fungi and rhizobia on soybean plants need further research.

Also, co-inoculation with mycorrhizal consortium and rhizobia (R1MY) significantly enhanced soybean yield as indicated by pod number, pod fresh weight, seed number and seed fresh weight in the $70 \%$ FC but not in the $100 \%$ FC (Table 3). These outcomes further showed that there was a synergistic impact between mycorrhizal consortium and rhizobia on soybean yield in this investigation and that this impact 'might' be dependent on water status. However, previous study by Wang et al. [45] indicated that such synergistic impact can be link to nutrient status. It is generally believed that mycorrhizal fungi principally benefit plants grown in soil environments where phosphorus is likely to hinder plant productivity by increasing the volume of soil penetrated by mycorrhizal hyphae compared to that of root hairs of non-mycorrhizal plants $[43,45]$ and in the current study, there was no addition of inorganic phosphorus and nitrogen to the soil and the natural soil total nitrogen was slightly low $(00.095 \%$-Table 1$)$ compared to that $(0.22 \%)$ reported by Ortiz et al. [26]. This low nutrient level of soil could be another reason (In addition to water status) for the synergistic impacts of dual inoculation with mycorrhizal consortium and rhizobia in this study. The universal consensus is that mycorrhizal fungi enhance phosphorus nutrient uptake in legumes which eventually improves plant development and nitrogen fixation [15, 16] and according to Xavier and Germida [46], dual inoculation with rhizobia species and compatible AMF can intensely improve pea growth and nutrient uptake. On the basis of this, we observed that the rhizobia and mycorrhizal consortium used in the present study enhanced soybean plants tolerance to drought and improved their 
productivity. Therefore, the fungal consortium is compatible with our rhizobia species and soybean cultivar, which may have prospect for agronomic application.

Acknowledgements ONI thanks National Research Foundation, South Africa/ The World Academy of Science African Renaissance for grant (UID105466) that has supported his Doctoral programme. OOB would like to thank the National Research Foundation, South Africa for grants (UID81192, UID99779, UID95111, and UID104015) that has supported research in our laboratory. Data have been presented previously in a conference titled: Annual Conference of the Association for General and Applied Microbiology 17-20 March 2019 at JohannesGutenberg-University, Germany by Ozede N. Igiehon and Olubukola O. Babalola. The Panacea to Food Insecurity Starts with Rhizobia, Mycorrhizal Fungi and Soybean bean in a Controlled Environment p.113-114. https://www.vaamkongress.de/fileadmin/congress/media/ vaam2019/druckelemente/VAAM2019_Abstractbook.pdf

Author Contributions ONI designed/performed the experiments and wrote the article. OOB supervised the work. Both authors approved the article for publication.

Funding National Research Foundation, South Africa/ The World Academy of Science African provided stipends for ONI for his PhD program and National Research Foundation, South Africa grants (UID81192, UID99779, UID95111, and UID104015) financially supported this work.

\section{Compliance with Ethical Standards}

Conflict of interest The authors declares that they have no conflict of interest.

Open Access This article is licensed under a Creative Commons Attribution 4.0 International License, which permits use, sharing, adaptation, distribution and reproduction in any medium or format, as long as you give appropriate credit to the original author(s) and the source, provide a link to the Creative Commons licence, and indicate if changes were made. The images or other third party material in this article are included in the article's Creative Commons licence, unless indicated otherwise in a credit line to the material. If material is not included in the article's Creative Commons licence and your intended use is not permitted by statutory regulation or exceeds the permitted use, you will need to obtain permission directly from the copyright holder. To view a copy of this licence, visit http://creativecommons.org/licenses/by/4.0/.

\section{References}

1. Pereira $\mathbf{J}$ (1993) Plant water deficits in Mediterranean ecosystems. Water deficits: Plant response from cell to community. Oxford: BIOS Scientific Publishers Ltd, 237-251.

2. M Ashraf L Wu 1994 Breeding for salinity tolerance in plants Crit Rev Plant Sci 131742

3. B Vinocur A Altman 2005 Recent advances in engineering plant tolerance to abiotic stress: achievements and limitations Curr Opin Biotechnol 16123132

4. WA Kasim ME Osman MN Omar IA Abd El-Daim S Bejai J Meijer 2013 Control of drought stress in wheat using plantgrowth-promoting bacteria J Plant Growth Regul 32122130
5. A Hsiao 2000 Effect of water deficit on morphological and physiological characterizes in Rice (Oryza sativa) J Agric 393 97

6. P Rahdari S Hoseini 2012 Drought stress: a review Int J Agron Plant Prod 3443446

7. NH Samarah 2005 Effects of drought stress on growth and yield of barley Agron Sust Dev 25145149

8. NO Igiehon OO Babalola BR Aremu 2019 Genomic insights into plant growth promoting rhizobia capable of enhancing soybean germination under drought stress BMC Microbiol 19159

9. CA Jaleel P Manivannan A Wahid M Farooq HJ Al-Juburi R Somasundaram R Panneerselvam 2009 Drought stress in plants: a review on morphological characteristics and pigments composition Int J Agric Biol 11100105

10. Barber SA (1995) Soil nutrient bioavailability: a mechanistic approach: John Wiley \& Sons.

11. Selvakumar G, Panneerselvam P, Ganeshamurthy AN (2012) Bacterial mediated alleviation of abiotic stress in crops. In: Bacteria in agrobiology: Stress management. Springer: 205-224.

12. M Hungria AA Franco JI Sprent 1993 New sources of high-temperature tolerant rhizobia for Phaseolus vulgaris L Plant Soil 149 103109

13. RM Augé 2001 Water relations, drought and vesicular-arbuscular mycorrhizal symbiosis Mycorrhiza 11342

14. RM Augé JL Moore DM Sylvia K Cho 2004 Mycorrhizal promotion of host stomatal conductance in relation to irradiance and temperature Mycorrhiza 148592

15. NO Igiehon OO Babalola 2017 Biofertilizers and sustainable agriculture: exploring arbuscular mycorrhizal fungi Applied Microbiol Biotechnol 10148714881

16. Igiehon NO, Babalola OO, Cheseto X, Torto B (2020) Effects of rhizobia and arbuscular mycorrhizal fungi on yield, size distribution and fatty acid of soybean seeds grown under drought stress. Microbiol Res 126640.

17. I Stancheva M Geneva G Zehirov G Tsvetkova M Hristozkova G Georgiev 2006 Effects of combined inoculation of pea plants with arbuscular mycorrhizal fungi and Rhizobium on nodule formation and nitrogen fixing activity Gen Appl Plant Physiol 46166

18. NO Igiehon OO Babalola 2018 Rhizosphere microbiome modulators: contributions of nitrogen fixing bacteria towards sustainable agriculture Int J Environ Res Public Health 15574598

19. N Aliasgharzad MR Neyshabouri G Salimi 2006 Effects of arbuscular mycorrhizal fungi and Bradyrhizobium japonicum on drought stress of soybean Biologia 61 S324 S328

20. Dodd IC, Belimov A, Sobeih W, Safronova V, Grierson D, Davies W (2004) Will modifying plant ethylene status improve plant productivity in water-limited environments. In: Handbook and abstracts for the 4th International Science Congress', Brisbane, Australia.

21. M Arshad B Shaharoona T Mahmood 2008 Inoculation with Pseudomonas spp. containing ACC-deaminase partially eliminates the effects of drought stress on growth, yield, and ripening of pea (Pisum sativum L.) Pedosphere 18611620

22. SSKP Vurukonda S Vardharajula M Shrivastava A SkZ 2016 Enhancement of drought stress tolerance in crops by plant growth promoting rhizobacteria Microbiol Res 1841324

23. L Zarik A Meddich M Hijri M Hafidi A Ouhammou L Ouahmane R Duponnois A Boumezzough 2016 Use of arbuscular mycorrhizal fungi to improve the drought tolerance of Cupressus atlantica G Comptes Rendus Biol 339185196

24. J Prakamhang P Tittabutr N Boonkerd K Teamtisong T Uchiumi M Abe N Teaumroong 2015 Proposed some interactions at molecular level of PGPR coinoculated with Bradyrhizobium diazoefficiens USDA110 and B. japonicum THA6 on soybean symbiosis and its potential of field application Appl Soil Ecol 853849 
25. R Aroca JJ Irigoyen M Sánchez-Díaz 2003 Drought enhances maize chilling tolerance. II. Photosynthetic traits and protective mechanisms against oxidative stress Physiol Plantarum 117540 549

26. N Ortiz E Armada E Duque A Roldán R Azcón 2015 Contribution of arbuscular mycorrhizal fungi and/or bacteria to enhancing plant drought tolerance under natural soil conditions: effectiveness of autochthonous or allochthonous strains J Plant Physiol 1748796

27. G Pacioni 1992 Wet-sieving and decanting techniques for the extraction of spores of vesicular-arbuscular fungi Methods Microbiol 24317322

28. O Masciarelli A Llanes V Luna 2014 A new PGPR co-inoculated with Bradyrhizobium japonicum enhances soybean nodulation Microbiol Res 169609615

29. Duncan DB (1955) Biometrics. Multiple range and F tests 11:1-42.

30. M Baslam N Goicoechea 2012 Water deficit improved the capacity of arbuscular mycorrhizal fungi (AMF) for inducing the accumulation of antioxidant compounds in lettuce leaves Mycorrhiza 22 347359

31. R Aroca Alguacil M Mar del P Vernieri JM Ruiz-Lozano 2008 Plant responses to drought stress and exogenous ABA application are modulated differently by mycorrhization in tomato and an ABA-deficient mutant (sitiens) Microbial Ecol 56704

32. X Zhu F Song S Liu T Liu X Zhou 2012 Arbuscular mycorrhizae improves photosynthesis and water status of Zea mays L. under drought stress Plant Soil Environ 58186191

33. N Goicoechea M Antolin M Sánchez-Díaz 1997 Gas exchange is related to the hormone balance in mycorrhizal or nitrogen-fixing alfalfa subjected to drought Physiol Plantarum 100989997

34. Q Wu R Xia 2006 Effects of arbuscular mycorrhizal fungi on leaf solutes and root absorption areas of trifoliate orange seedlings under water stress conditions Frontt Forestry China 1312317

35. Berglund AH, Larsson KE, Liljenberg CS (2004) Permeability behaviour of lipid vesicles prepared from plant plasma membranes-impact of compositional changes. Biochimica et Biophysica Acta (BBA)-Mol Cell Biol Lipids 1682:11-17.

36. Y Bashan G Holguin LE De-Bashan 2004 Azospirillum-plant relationships: physiological, molecular, agricultural, and environmental advances (1997-2003) Canadian J Microbiol 50521577

37. JM Ruiz-Lozano R Porcel C Azcón R Aroca 2012 Regulation by arbuscular mycorrhizae of the integrated physiological response to salinity in plants: new challenges in physiological and molecular studies J Exper Bot 6340334044

38. Dong D, Liu T, Yuan J, Xie A, Tu T (2002) Artificial neural networks method for oil systems identification and its applications. In: Proceedings of the 4th World Congress on Intelligent Control and Automation 2952-2955.

39. Manoharan P, Shanmugaiah V, Balasubramanian N, Gomathinayagam S, Sharma MP, Muthuchelian K (2010) Influence of AM fungi on the growth and physiological status of Erythrina variegata Linn. grown under different water stress conditions. Eur J Soil Biol 151-156.

40. F Tajini M Trabelsi J Drevon 2012 Comparison between the reference Rhizobium tropici CIAT899 and the native Rhizobium etli $12 \mathrm{a} 3$ for some nitrogen fixation parameters in common bean (Phaseolus vulgaris L.) under water stress Afr J Microbiol Res 64058 4067

41. Igiehon NO, Babalola OO (2018) Below-ground-above-ground Plant-microbial Interactions: Focusing on Soybean, Rhizobacteria and Mycorrhizal Fungi. Open Microbiol J 12.

42. BC Nwachukwu AS Ayangbenro OO Babalola 2021 Elucidating the rhizosphere associated bacteria for environmental sustainability Agriculture 1175

43. Igiehon NO, Babalola OO (2017) Biofertilizers and sustainable agriculture: exploring arbuscular mycorrhizal fungi. Appl Microbiol Biotechnol 1-11

44. Enebe MC, Babalola OO (2018) The influence of plant growthpromoting rhizobacteria in plant tolerance to abiotic stress: a survival strategy. Appl Microbiol Biotechnol 1-15.

45. X Wang Q Pan F Chen X Yan H Liao 2011 Effects of co-inoculation with arbuscular mycorrhizal fungi and rhizobia on soybean growth as related to root architecture and availability of $\mathrm{N}$ and $\mathrm{P}$ Mycorrhiza 21173181

46. LJ Xavier JJ Germida 2003 Selective interactions between arbuscular mycorrhizal fungi and Rhizobium leguminosarum bv. viceae enhance pea yield and nutrition Biol Fert Soils 37261267

Publisher's Note Springer Nature remains neutral with regard to jurisdictional claims in published maps and institutional affiliations. 